\title{
A crítica como recepção histórica: interfaces entre o pensamento de Walter da Silveira e o cinema brasileiro
}

\section{Rafael Oliveira Carvalho}

Mestre pela Universidade Federal da Bahia. Membro do Grupo de Pesquisa Recepção e Crítica da Imagem (GRIM). Bolsista da Fundação de Amparo à Pesquisa do Estado da Bahia (FAPESB). E-mail: rafaolicarvalho@gmail.com
Resumo: A partir dos escritos do crítico e ensaísta baiano Walter da Silveira, buscamos entender como o cinema brasileiro foi avalizado e julgado por ele em alguns periódicos da Bahia entre as décadas de 1950 e 1960. Partilhamos das ideias conceituais de David Bordwell (1991) e Janet Staiger (1992; 2000) que entendem a atividade crítica como parte fundamental do processo de recepção da obra fílmica a partir de sua contextualização histórica e não somente na análise das características imanentes do texto crítico. No caso de Walter da Silveira, observamos que seu olhar se equilibra entre a valorização do cinema nacional e o distanciamento analítico importante para qualquer avaliação crítica.

Palavras-chave: Walter da Silveira; crítica cinematográfica; cinema brasileiro; recepção histórica.

Title: Criticism as historical reception: interfaces between the thought of Walter da Silveira and Brazilian cinema

Abstract: From the writings of the baiano film critic and essayist Walter da Silveira, we try to comprehend how the Brazilian cinema was endorsed and judged by him in some newspapers from Bahia between the 1950s and 1960s. We share the conceptual ideas from David Bordwell (1992) and Janet Staiger (1992; 2000) that understand the critic work as a fundamental part of the process of reception of the film from its historical context and not only from the immanent features of the critic text. In the case of Walter da Silveira, we noted that his view equilibrates between the valorization of the national movies and the analytical detachment important in any critical evaluation.

Keywords: Walter da Silveira; film criticismo; Brazilian cinema; historical reception.

\section{Por uma recepção histórica}

Walter da Silveira, crítico ou ensaísta de cinema, cineclubista e professor. Essas são algumas das atividades que o reconhecido intelectual baiano exerceu em torno das discussões da arte cinematográfica na Bahia. As críticas e artigos que escreveu em diversos periódicos na Bahia, entre as décadas de 1930 e 1960, bem como suas atividades em torno da propagação do pensamento cinematográfico, tornaram-no figura respeitada e referenciada como profissional que detinha certo conhecimento acumulado sobre o cinema, uma espécie de mentor intelectual de toda uma geração de pessoas, a despeito da formação acadêmica de Silveira ser em Direito. Nas palavras de André Setaro: "A partir de Walter, os baianos começaram a considerar o cinema autêntico veículo da expressão artística" (2010: 52). 
${ }^{1}$ Este artigo é parte do trabalho dissertativo desenvolvido por Rafael Carvalho e orientado pela profa. Dra . Regina Gomes, que se deteve na obra crítica de Walter da Silveira e abarca uma parte maior de seus escritos.
Este artigo se detém em analisar algumas críticas cinematográficas publicadas por Silveira sobre filmes nacionais com o intuito de compreender de que forma esses textos críticos foram importantes para o pensamento reflexivo sobre o cinema nacional numa época e lugar em específico ${ }^{1}$. Os textos que versam sobre filmes do cinema brasileiro, com ênfase também na produção baiana, podem ser vistos não só como traços de recepção daquilo que era assistido à época nos cinemas, mas também como uma forma de valorização da cinematografia nacional, comprometimento do qual Silveira era filiado. E isso independia da valoração que ele fazia sobre os filmes. O simples fato de jogar luz sobre esses trabalhos, colocálos em pauta e discuti-los é também uma maneira de chamar atenção para essas obras. São evidentes alguns textos, não críticos (na sua maioria ensaios e algumas reportagens), publicados por Silveira que demonstram como o cinema nacional era uma preocupação central no seu pensamento.

Ao se debruçar sobre os escritos críticos de Silveira, é imprescindível considerá-los numa dada confluência contextual. Busca-se aqui um horizonte interdisciplinar de análise em que o objeto estudado tem valor não só através de suas características imanentes, mas também a partir do entorno histórico-contextual em que foi produzido. É preciso não perder de vista que a crítica cinematográfica também possui funções culturais estabelecidas, linhas editoriais, certos objetivos, posições e interesses que ela própria assume como política a ser difundida. Daí a importância de se pensar a confluência contextual como marca preponderante para a análise de recepção.

David Bordwell (1991) e Janet Staiger (1992; 2000) são dois dos principais pesquisadores do cinema a pensar a recepção das obras fílmicas sem desvinculála dos condicionantes históricos. Em Making meaning (2001), Bordwell critica duramente o papel de destaque que a interpretação ocupa no âmbito da crítica cinematográfica (o autor chega a defender que os tempos áureos da crítica centrada na interpretação já acabaram). Os objetivos do pesquisador estão no esforço de "mostrar como uma poética histórica do cinema pode iluminar o problema de como, quando e em que medida os filmes significam" (1991: XIV).

Nesse sentido, Bordwell acredita que a inclusão da pesquisa histórica enriquece a abordagem do filme e aponta para caminhos que possam fazer a significação de uma obra cinematográfica mais abrangente do que aquelas adquiridas a partir dos mesmos procedimentos críticos de caráter textual que geralmente chegam a respostas comuns e repetitivas. Isso não quer dizer que seja preciso romper com a tradição da interpretação, longe disso, mas antes expandir o objeto de estudo incluindo as variantes de público e período, situando-o dentro de uma pesquisa histórica mais ampla. Sua argumentação é de como essa poética do cinema oferece certos conceitos teóricos capazes de capturar pistas significantes de intersubjetividade no processo de interpretação dos filmes. Isso porque, para o autor, os significados seriam construídos historicamente, como convenções sociais.

Com Interpreting films (1992), Staiger vai conferir lugar de destaque para a figura do espectador, inserindo-o num dado contexto para que possa pensá-lo como um sujeito ativo que analisa e absorve a obra fílmica a partir dos conceitos, pressupostos e posições que estão em evidência naquele dado momento e nos lugares em que ele circula, compartilhado pelas pessoas com quem ele se identifica e possui proximidade. São os vestígios de recepção deixados por eles que servem aos estudos de caso. A autora fala em "leitor histórico" para definir esse sujeito ativo que interpreta segundo sua condição de indivíduo pertencente a um contexto específico que lhe oferece certos modos de raciocínio compartilhado que estão disponíveis naquele momento. Vale destacar que estamos lidando com o crítico de cinema também ele um leitor, mesmo que sui generis, que faz significar a obra fílmica e expressa seu ponto de vista a partir do lugar que conquista enquanto crítico reconhecido (CUNHA, 2004).

Segundo Staiger, os estudos da recepção, ao utilizar uma metodologia que leva em consideração somente a reação do leitor/espectador sobre determinado 
produto cultural, acaba por representar esse sujeito de forma "ahistórica", fora de seu tempo, tornando-o mais um indivíduo ficcional do que um dado real mais significativo. Como escreve o pesquisador e crítico literário Antonio Marcos Pereira: "cada texto produzido ao mesmo tempo se inscreve e é atravessado por uma história que marca a pessoa que o produz de uma certa maneira. Fora dessa história não há texto, não há leitor, não há escritor, não há literatura nem, evidentemente, sua crítica" (PEREIRA, 2012: 31).

Staiger defende que a interpretação, não só de uma obra fílmica, mas de qualquer artefato cultural, não possui significados imanentes no texto, mas sim variações de bases históricas que apontam para condições sociais, políticas e econômicas que, por sua vez, interferem nesses significados. A interpretação seria moldada, portanto, pelos sujeitos históricos inseridos num dado contexto social, e é a partir de uma abordagem contextual e materialista que precisa ser estudada. Através desse viés metodológico, que ela mesma chama de histórico-materialista, pontua o seguinte: "eu não interpreto os textos, mas tento fazer uma explicação histórica do ato de interpretar um texto" (STAIGER, 1992: 81).

No caso de Walter da Silveira, é preciso resgatar todo um trabalho feito em torno do cinema e da experiência cinéfila que ele desenvolveu em paralelo, incentivando a produção local, desenvolvendo a prática do cineclubismo, atuando na área acadêmica e professoral, participando ativamente das discussões em torno da sétima arte e mesmo da crítica cinematográfica, analisando a própria história do cinema em consonância com aquilo que acontecia na Bahia. Ao mesmo tempo sujeito observador do cinema e de suas manobras de realização e difusão para um certo público espectador, era também ele mesmo um personagem ativo na construção de uma cultura cinéfila na Bahia daquele período. Ele moldava e era moldado pelas circunstâncias contextuais da Bahia cinéfila, especialmente entre as décadas de 1950 e 1960.

A partir dos pressupostos teórico-metodológicos da recepção de viés histórico defendidos por Bordwell e Staiger, este trabalho de análise pretende se debruçar sobre as críticas que Silveira desenvolveu acerca do cinema brasileiro em confluência com os dados contextuais do período. O recorte no conjunto de textos analisados privilegia as críticas feitas durante as décadas de 1950 e 1960 por serem as mais representativas de uma fase já amadurecida do autor, além de ser esse o momento

${ }^{2}$ Todas as críticas foram retiradas da coletânea Walter da Silveira: o eterno e o efêmero (2006) organizada por José Umberto Dias, edição em quatro volumes que reúne grande parte da produção textual do escritor. Embora haja um esforço de reunir os escritos de Silveira, muitos de seus textos não constam da coletânea e outros foram perdidos. O presente artigo se baseia nos textos publicados nessa coletânea. em que ele mais publicou em termos quantitativos ${ }^{2}$. Por não ser jornalista de formação, nem trabalhar como contratado dos jornais e revistas, sendo um colaborador convidado, seus textos não possuíam uma periodicidade fixa.

Sem a rigidez de tentar enquadrar Silveira numa classificação que possa identificálo como um tipo específico de crítico, a nossa proposta está centrada na identificação de uma grade de leitura que Silveira utilizava para interpretar e ajuizar sobre as obras do cinema brasileiro, em confluência clara com o momento histórico em que vivia e na qual aqueles produtos eram realizados e consumidos pelo público.

\section{Walter da Silveira e a recepção ao cinema nacional}

A responsabilidade crítica só faz crescer diante do filme brasileiro. Porque em seu território os passos devem ser mais fortes e decisivos. Não há maior dificuldade em opinar sobre um filme estrangeiro: as matrizes críticas vêm de fora. Para falar do filme nacional, o crítico necessita de originalidade, pois tem de interpretá-lo a partir de si mesmo. Muitas omissões e hostilidades que andam por aí derivam desta causa: o requisito de uma renovação constante de juízos próprios, sem amparo exterior, quando a fita proposta à crítica é uma fita nacional (SILVEIRA, 1969: 38).

Levando adiante seu intuito de educar o público para o cinema através do fazer crítico, percebemos que, ao falar do cinema nacional, Walter da Silveira trazia consigo o encargo de olhar para essa produção com mais apuro. Com exceção de algumas obras 
${ }^{3}$ É o próprio Walter da Silveira que relata isso, desanimado pelo próprio desinteresse da crítica nacional em acompanhar a trajetória do filme nacional, deixando claro que também cobriam o festival jornalistas brasileiros que eram correspondentes estrangeiros na Europa ou críticos que já estavam na França na época do evento. $E$ acrescenta: "Mas outros, sobretudo aqueles que sempre negaram as possibilidades brasileiras para o cinema, deveriam estar aqui, para sentir o frêmito enorme que agitou o Festival com a mise-en-scène de Anselmo Duarte" (SILVEIRA, 1962: 258). que tiveram destaque fora do país, nomeadamente alguns filmes pertencentes ao Cinema Novo, além de alguns outros poucos que conseguiram quebrar essa barreira, o filme nacional encontrava seu maior público e críticos dispostos a discuti-lo dentro do próprio país, apesar dos problemas de distribuição das obras. De qualquer forma, a valoração do produto nacional precisava ser mais cautelosa e, segundo Silveira, longe de bairrismos. A preocupação com o conteúdo da obra, traduzido por meio dos fatores estéticos, era o ponto norteador da análise do crítico.

Pensar no caso de recepção ao filme O pagador de promessas (Anselmo Duarte, 1962) é pertinente para introduzir essa análise e sentir o cuidado com que Silveira tratava a crítica enquanto atividade séria e profissional, precisando ser, inclusive, discutida por quem a exercia. Selecionado para a competição oficial do prestigiado Festival de Cannes, de onde saiu com a Palma de Ouro, o filme de Anselmo Duarte se mantém até hoje como o único longa-metragem nacional a conquistar o prestigioso prêmio. Walter da Silveira foi o único crítico brasileiro que viajou até Cannes ${ }^{3}$, junto à comitiva brasileira, a fim de acompanhar a repercussão da obra no exterior, aproveitando também para fazer a cobertura do festival como crítico de cinema.

Assim como os brasileiros presentes no evento, e fazendo coro à crítica especializada que cobria o festival, o prêmio máximo concedido ao filme foi saudado por Silveira como uma grande vitória para o cinema nacional, já que, rodado na Bahia, o filme carregava o espírito e as imagens daquela terra. Sendo ele um entusiasta do cinema nacional e defensor da produção local, deixou registrado a admiração por ter visto o filme ser consagrado, não só pelo júri composto por nomes variados do meio cinematográfico mundial, mas também pela crítica especializada e pelo público.

Silveira também esteve bastante próximo da produção do filme, fazendo inclusive uma pontinha como ator, interpretando o dono de um bar. Ou seja, as relações dele com a obra poderiam prever um olhar mais condescendente ou mesmo de isenção de opinião, dada a proximidade com o projeto. Mas mesmo assim, ele preferiu avaliar e deixar clara sua posição sobre o filme, com incisão, analisando-o em paralelo com aquilo que o festival exibiu em termos de produção cinematográfica mundial e que, para ele, representava uma grande reunião do melhor do cinema contemporâneo de autor. Silveira não se eximiu de apontar falhas da obra, como a transposição de um texto teatral que, na opinião dele, não encontrou um viés de expressão mais cinematográfica, além de identificar problemas de continuidade narrativa, criticando também a inclusão exagerada de temas nacionalistas a fim de demarcar a cultura brasileira.

Como crítico, tinha consciência, porém, de que $\mathrm{O}$ pagador de promessas não fora o melhor filme da competição. [...] Posso, contudo, afirmar que o júri foi injusto? Evidentemente, os filmes de Cacoyannis, Antonioni, Bresson, Buñuel, como obras da arte cinematográfica, expressão do pensamento, linguagem, são muito superiores a $\mathrm{O}$ pagador de promessas. Anselmo Duarte está longe, como cineasta, de qualquer dos quatro (SILVEIRA, 1962a: 264).

Do entusiasmo inicial de louvação para o filme que teve a oportunidade de participar da competição em Cannes e da aclamação da crítica que ele fez questão de descrever nos jornais, Silveira procurou deixar de lado o patriotismo e a ânsia de sucesso pelo projeto brasileiro. Nas suas próprias palavras: "Pessoalmente, distingo minha condição de brasileiro da de crítico" (SILVEIRA, 1962a: 264).

Apesar de considerar a posição de Silveira sobre seu próprio ofício e entender o distanciamento com que ele pretendia realizá-lo como profissional imparcial, essa posição deve ser relativizada no percurso de análise uma vez que a perspectiva da recepção histórica entende justamente os sujeitos como inseridos num confluência contextual que molda e interfere o seu olhar (STAIGER, 1992; 2000). Querendo 
ou não, sua posição como brasileiro (e baiano), muito próximo da equipe de realização do filme, interviu, de uma forma ou de outra, nas suas avaliações.

Nesse embate teórico, nos deteremos, a partir de então, a observar algumas recorrências observadas no grupo de críticas que ele escreveu sobre os filmes nacionais, fazendo relação com o momento histórico no sentido de compreender a forma como o crítico baiano lia o cinema brasileiro. Também não buscamos respostas que avalizem e apontem juízos de valor sobre a obra em si, sobre suas características estéticas e artísticas imanentes, mas antes sua demarcação dentro de um contexto de produção nacional e recepção particular.

\section{O cinema brasileiro em contexto}

Uma das principais regularidades na escrita crítica de Walter da Silveira referese a uma abordagem feita não só da fita em si, mas daquilo que ela representa para a cultura cinematográfica do Brasil naquele momento. Poucos são os textos de Silveira que já começam abordando a obra analisada. Como introdução para a apreciação fílmica, a discussão de uma produção brasileira é uma marca primordial dos textos analisados, no sentido de pensar uma escola nacional de cinema, um novo cinema nacional que está florescendo, a busca pela representação de um povo e sua cultura na tela e o lugar do próprio cinema brasileiro em relação ao estrangeiro. Os filmes não podem ser vistos isoladamente, mas sim dentro de um contexto de produção e formatação de uma ideia de cinematografia que torne possível falar em termos de um projeto de cinema nacional.

Poderemos encontrar textos de Walter da Silveira que revelam sua atenção para a produção local a partir dessa preocupação em se pensar a possibilidade de uma filmografia dita brasileira. É o caso de "Esta é a hora do Cinema Nacional", publicado já em 1943 no jornal O Imparcial, em que ele faz considerações tais como:

Nesse momento, nasce a possibilidade do cinema nacional, [...]. As nossas casas de exibições estão projetando os filmes mais medíocres ou reprisando películas já muito reprisadas. O público vai ainda ao cinema porque em cidades como Salvador, a única diversão existente é a cinematografia. [...] Não vou dizer aqui uma tolice: a de afirmar que o cinema brasileiro pode preencher a lacuna deixada pelo cinema estrangeiro. Afirmo, entretanto, que o cinema nacional deve aproveitar o momento para criar mais e melhor, enchendo os cartazes com seu anúncio. [...] Não é uma ilusão, é um ideal. E nada tem de romântico. Assenta nas condições mesmas da vida que aí está. É só olhar querendo ver, esta é a hora do cinema nacional (SILVERA, 1943: 93-94).

\footnotetext{
${ }^{4}$ Movimento que se formou a partir da produção local de alguns filmes entre 1959 e 1964, imprimindo nas telas obras com as manifestações culturais e sociais da Bahia, aliadas a uma estética peculiar de realização a baixo custo. Roberto Pires é quem inaugura essa fase de produção com o lançamento de Redenção (1959), considerado o primeiro longa-metragem baiano.
}

E serão muitos textos com esse teor de encorajamento e valoração que ele fará no decorrer dos anos, preocupado não só com a qualidade dos filmes, mas também com as políticas de incentivo, os modos de produção, as formas de exibição e a aceitação do púbico para esse cinema brasileiro. Nesse mesmo caminho, a partir de determinado momento, Silveira também vai se dedicar a discutir muito a produção baiana, assunto em efervescência especialmente com a deflagração do Ciclo de Cinema da Bahia ${ }^{4}$ e toda a movimentação no estado como polo de produção cinematográfica.

Nas primeiras críticas analisadas por Silveira sobre filmes nacionais, entre os anos de 1953 e 1954, já havia essa preocupação em discutir, e mesmo um anseio em identificar, uma produção brasileira que apresentasse uma unidade narrativa que pudesse representar o país. Ao falar de $O$ cangaceiro (Lima Barreto, 1953), Silveira chega a declarar o lançamento do filme como uma espécie de marco de um certo projeto nacional de cinema brasileiro: "De nossa parte, jamais esperávamos que Lima Barreto, não obstante o mérito indiscutível de Painel e Santuário, dois films d'art, conseguisse a posição singular de fundador de uma escola brasileira de cinema" (SILVEIRA, 1953a: 289). Essa busca pela concretização de um cinema 
dito nacional (assim como a gênese de uma cinematografia baiana), ou mesmo de uma vertente temático-estilística que se diferencie das produções comuns, como é o caso acima, será uma constante nos escritos de Silveira, inclusive nos vários ensaios publicados sobre o tema no decorrer de sua carreira. Nas críticas, isso ganha ares de contextualização que serve de apreciação para o próprio filme enquanto lugar ocupado dentro da produção nacional.

Nos textos sobre Sinhá moça (Tom Payne e Oswaldo Sampaio, 1953) e Floradas na serra, (Luciano Salce, 1954) a importância de uma companhia produtora de filmes como a Vera Cruz (também responsável por $O$ cangaceiro) é posta como ponto de discussão relevante sobre a construção do que seria o cinema nacional e suas preocupações temáticas, assim como seu próprio fim é refletido para subsidiar a análise do filme dentro do "legado" por ela deixada:

Desde O cangaceiro [...] a Cinematográfica Vera Cruz vem tentado encontrar, nos fatos e costumes do nosso povo, a singularidade nacional de um novo cinema. [...] Se retirarmos ao filme de Lima Barreto a admirável música folclórica que tanto o identifica de nacionalidade, o novo filme da Vera Cruz [Sinhá Moça] o excede como pensamento e imagem do Brasil (SILVEIRA, 1953a: 302).

Se for certo que a Cinematográfica Vera Cruz não produzirá mais, Floradas na serra deve ser o seu último filme, e o mais esperado também. [...] Diz-se, da Vera Cruz, que, se, de um ponto de vista estético, situou o filme brasileiro numa categoria internacional, com $\mathrm{O}$ cangaceiro e Sinhá Moça, do ponto de vista econômico, com a sua desmedida ambição de fabricar superproduções sem garantia de rentabilidade, provocou uma intensa desordem financeira em nossa indústria cinematográfica, arrastando-a à caótica situação atual (SILVEIRA, 1954: 396).

Nessa perspectiva nacionalista de anseio por um cinema dito nosso, Walter da Silveira sempre irá enxergar a produção nacional como um conjunto, num mesmo sentido histórico que vai abrindo ou fechando as portas para um contexto de cinematografia local. Nas críticas, as abordagens introdutórias que se dedicam à situação do cinema brasileiro, feitas antes de entrar na análise do filme propriamente, objetivam retomar a história do cinema nacional e dos filmes que se destacaram, sendo essa característica uma constante como forma de pensar a trajetória dessa cinematografia.

No trecho sobre Floradas na serra, a questão do fim da Cinematográfica Vera Cruz leva a uma discussão de (des)valoração dos filmes anteriores que foram produzidos pela empresa, tendo esta, por sua vez, carregado certas virtudes e também defeitos que marcaram o cinema nacional por um certo período. Para falar de Redenção (Roberto Pires, 1959), considerado o primeiro longa-metragem baiano, Silveira retoma o histórico não só da produção de pequenos curtas, como remonta à chegada do próprio cinema às terras da Bahia e do pioneirismo do lançamento de uma revista semanal de cinema, tudo isso numa tentativa de entender como o filme de Roberto Pires pôde surgir naquele dado momento. Da mesma forma, toda a abordagem inicial de Sol sob a lama (Alex Viany, 1963), é feita numa comparação com A grande feira (Roberto Pires, 1961) já que o primeiro filme foi produzido em resposta ao segundo, envolvendo a representação do povo humilde da feira de Água de Meninos, das lutas por eles enfrentadas e dos problemas sociais que sofriam, representação essa considerada equivocada pelos produtores e pelo diretor de Sol sob a lama. Esse filme não poderia ser avalizado senão em paralelo com o anterior, sobre o qual Silveira também escreveu em separado.

Já no texto sobre Deus e o Diabo na terra do sol (Glauber Rocha, 1964), datado de 1965, as discussões sobre a representação do Nordeste e do cangaço remontam justamente a $O$ cangaceiro, onze anos antes, tido por ele como o momento em 
que esta temática ganha destaque como assunto principal no cinema brasileiro. Da mesma forma, a própria trajetória de Glauber Rocha à frente da direção de filmes como Barravento (1962) e de seu curta O pátio (1959) surgem como pontos de discussão em que Silveira se detém para situar o cineasta baiano no centro dos fatos cinematográficos daquele período e pensar na realização e profusão de um filme como aquele que acabava de ser lançado, considerado por Silveira uma obra revolucionária e também um momento de transição para o cinema brasileiro.

Nesse sentido, é interessante perceber como a história da produção cinematográfica brasileira, em alguns de seus momentos marcantes, se reflete no comentário do próprio filme. Do período das grandes produtoras (da qual a Vera Cruz foi uma das últimas), passando pelo Ciclo de Cinema da Bahia, até o florescimento do Cinema Novo, a crítica de Walter da Silveira ao cinema brasileiro sempre procurou colocar o filme em meio ao universo maior do contexto, e não somente partir de suas marcas imanentes, estéticas e temáticas, que se percebe na fita fílmica.

\section{O Brasil na tela}

No contexto em que a Vera Cruz representou uma esperança de realização de grandes filmes, a partir de um refinamento maior de sua produção, inclusive importando técnicos e profissionais estrangeiros, numa tentativa de se aproximar da estética clássica do cinema norte-americano de primeira linha, Silveira deixa claro a satisfação de poder contar, no Brasil, com uma produtora que enxerga o filme no seu apuro técnico. No entanto, também critica duramente o fato da empresa escolher temáticas para os filmes que não representassem a cultura nacional. Para ele, essa era uma característica primordial para se pensar em um projeto de cinema brasileiro. "Um dos erros inegáveis da Vera Cruz consistiu sempre na temática de suas produções" (SILVEIRA, 1954: 397), escreveu na crítica de Floradas na serra, apontado como a adaptação de um romance sem essência nacional, cuja história de amor entre um homem e uma jovem que acabou de ser diagnosticada com tuberculose era tratada de forma romanceada e individualista.

Os costumes, o povo, a geografia, as manifestações culturais, os valores, a história, essas sim deveriam ser marcas perceptíveis nos filmes para que representassem uma nação. Silveira não deixava de criticar duramente o filme que não apresentasse características e temáticas de caráter nacionalista. É o caso do texto sobre Estranho encontro (Walter Hugo Khouri, 1958), em que é possível encontrar o seguinte questionamento:

Estranho encontro pertence ao cinema brasileiro? Em nenhum país do mundo a existência de uma escola cinematográfica nacional nasceu da aparência da obra de arte fílmica, porém do seu espírito. [...] É sempre através do que há de distinto e de próprio que os vários países se legitimam e se afirmam artisticamente. Não percebeu essa simplicidade o autor de Estranho encontro. Por isso, ao invés de buscar uma estética cinematográfica brasileira para o seu filme, procurou se evadir dela (SILVEIRA, 1959a: 72).

Pode-se criticar a visão exacerbadamente nacionalista de Silveira ao valorizar como produto nacional somente aqueles filmes que deixassem exposto na tela alguma marca cultural do país, algo que pudesse caracterizá-lo como tal, desmerecendo assim obras mais introspectivas e de viés puramente psicológico, sem traços explícitos de "brasilidade", como faz Walter Hugo Khoury, já que isso faz parte de seu estilo particular como cineasta. Se essa autoralidade era bastante valorizada quando Silveira tratava dos filmes de diretores mundiais, na crítica ao cinema nacional ela não era um critério de análise primeiro, de destaque, assim como a "desnacionalização" pesava negativamente sobre o filme. Era preciso que antes o cineasta pudesse mostrar a face da cultura brasileira para depois demonstrar sua faceta de cineasta com personalidade cinematográfica. No 
entanto, pode-se compreender que essa posição faz parte da necessidade em descobrir uma cinematografia reconhecidamente brasileira, algo que a crítica brasileira, de uma forma geral, começava a buscar por aquela época.

É nessa mesma perspectiva que surge um dos germes do Cinema Novo como catalisador de uma mentalidade que busca valorizar uma cinematografia, temática e esteticamente, relacionadas à realidade social e em termos de capacidade de produção cinematográfica no Brasil. Nas palavras de Glauber Rocha (1981):

O Cinema Novo é uma questão de verdade e não de fotografismo. Para nós, a câmera é um olho sobre o mundo, o travelling é um instrumento de conhecimento, a montagem não é demagogia mas a pontuação do nosso ambicioso discurso sobre a realidade humana e social do Brasil! (ROCHA, 1981: 52).

É possível perceber nesse discurso a mesma visão propagada por Silveira sobre a necessidade de um cinema que reflita seu próprio espaço de origem, não só nas temáticas escolhidas, mas também na maneira como isso é levado para a tela via recursos da linguagem cinematográfica, através de uma estilística fílmica própria. Essa é também uma visão que ganha reforço através de uma mentalidade na crítica brasileira que passa a reconhecer a perspectiva social e cultural nos filmes nacionais, com destaque para as ideias de Paulo Emilio Salles Gomes para quem o cinema nacional precisa ser uma representação do próprio estado de subdesenvolvimento social do país. A vontade de ver refletida e problematizada na tela a realidade brasileira alcança, no âmbito do pensamento cinemanovista, um caráter de urgência que precisa levar a uma linguagem que inspire a revolução social, especialmente nos países do então chamado Terceiro Mundo, como preconizava seus representantes. Para tanto, era preciso não se render ao modelo de produção dos grandes centros produtores no mundo, dito de "qualidade", buscando, por outro lado, uma estética que estivesse a serviço desse propósito, dentro das possibilidades técnicas que o Brasil dispunha à época.

No percurso de análise das críticas aos filmes brasileiros, porém, é possível encontrar uma exceção a essa regra. Ao falar de Redenção, o crítico coloca: "Afora o fato de ser Redenção um filme com capitais baianos, escrito e dirigido por um baiano, interpretado por baianos, a presença da Bahia é um simples presença de paisagem" (SILVEIRA, 1959b: 77). Mais adiante no texto, depois de apontar certos defeitos e problemas de cunho cenográficos e estético, ele arremata:

Nesse filme, onde os defeitos se alternam com as qualidades, há pelo menos uma que o consagra ao contrário da imensa maioria dos filmes nacionais. Redenção só existe e vale como cinema, não é uma obra subalterna de qualquer origem extracinematográfica (SILVEIRA, 1959b: 78).

Estamos, portanto, diante de um filme baiano, mas sem as características nacionalistas e mesmo regionais que ele prezava ver nas fitas, mas mesmo assim segue reconhecido por Silveira como filme da terra e de valor, apesar dos muitos defeitos narrativos apontados. Isso porque, na construção narrativa, o crítico encontra uma qualidade imanente que valida a obra não mais como filme nacional, mas agora como trabalho de expressão cinematográfica, para além de ser um marco do cinema realizado na Bahia.

\section{Consolidação e euforia}

É com Deus e o Diabo na terra do sol, a partir de seu lançamento em 1964, que a posição do cinema brasileiro chega a outro patamar de consolidação na visão de Silveira: "A história do nosso cinema é, aliás, a história de uma crise permanente: nunca atingimos um instante de euforia" (SILVEIRA, 1959a: 70), diz o crítico em março 
de 1959 na introdução do texto sobre Estranho encontro, revelando justamente esse sentimento por ver o cinema nacional como algo de maior grandeza. No entanto, quando essa euforia pareceu ter chegado com a surpreendente vitória de o pagador de promessas no Festival de Cannes, o crítico preferiu a parcimônia para colocar o filme no lugar que ele julgava merecedor naquele momento:

Com a Palma de Ouro, ainda não assumimos uma posição de relevo na cinematografia mundial. Tenhamos humildade para senti-lo e dizê-lo. Mas, com O pagador de promessas, nasce para o Brasil o compromisso de justificar, com filmes ainda melhores, o grande prêmio de Cannes (SILVEIRA, 1962a: 264).

Mesmo assim, havia uma animação, uma ânsia por uma cinematografia que até então ainda precisava crescer, talvez numa posição um tanto dura do crítico na reticência em reconhecer os méritos de uma produção que até aquele momento já tinha rendido bons frutos para a produção nacional. Sem dúvidas, Silveira não se deixava levar pela agitação e muito menos se influenciava facilmente pela premiação importante, preferindo se apegar a sua própria análise da obra para fazer os juízos de valor sobre o filme em si, e com isso construindo sua visão pessoal da posição em que se encontrava o cinema brasileiro num contexto maior. Na crítica a Vidas secas (Nelson Pereira dos Santos, 1963) ele afirma:

${ }^{5}$ Vidas Secas recebeu o prêmio de melhor filme da OCIC (Organização Católica Internacional de Cinema) e o prêmio dos Cinemas de Arte. Fonte: http://www.festival-cannes.fr/pt/ article/57959.html.
Provavelmente, Vidas secas não seria no Brasil tão admirado se o estrangeiro não o consagrasse: ainda resiste entre nós um sentimento colonial de admiração pelos reflexos mundiais da cultura brasileira. Mas os dois prêmios de Cannes ${ }^{5}$, os louvores da crítica francesa, de 1965 na França, deram para convencer a opinião nacional de que realmente Nelson Pereira dos Santos é um cineasta legítimo, um homem do cinema para ficar. [...] Aqui não há, certamente, o cinema de autor, tão defendido e proclamado como única saída moderna para o impasse do filme como arte e do cinema como indústria. Mas, existe, sem dúvida, um exemplo notável de transposição da literatura para o cinema (SILVEIRA, 1966: 185).

Consciente dessa predisposição generalizada em utilizar como critério de valorização o reconhecimento exterior, o crítico já expunha publicamente sua aversão a esse procedimento. E o filme de Nelson Pereira dos Santos acaba por ser visto através da abordagem subjetiva do crítico, numa posição que hoje certamente seria renegada por muitos estudiosos e pesquisadores. De qualquer forma, nota-se que o valor do filme é encontrado por ele através de certo aspecto (a notável qualidade da adaptação literária) defendido como aquilo que garante o lugar de destaque a ser dado a Vidas secas, visto por ele como um marco do cinema - e da literatura - nacional. Seria, portanto, uma posição de valorização daquilo que se depreende textualmente da obra e não algo que dependa de fatores exteriores a ela.

Entre expor sem restrições os problemas dos filmes e mesmo assim demarcar os percursos que o cinema nacional estava perfazendo, a partir dessas pequenas conquistas, como passos em direção a um nível de qualidade ainda aquém do esperado, para o crítico, os filmes brasileiros já mostravam sinais de que podia se equiparar às grandes obras do cinema mundial. Essa é uma preocupação clara nos escritos de Silveira, sentida nesse texto, mas que reflete um pensamento que ele expõe em vários artigos publicados em periódicos, como se o cinema de grandes diretores do mundo possuíssem um patamar de qualidade artística tal a ser alcançada pelos filmes brasileiros, ao mesmo tempo em que estas precisavam preservar as marcas culturais do país, deixando-as expostas na tela. Mas esse reconhecimento deveria vir pelas qualidades intrínsecas percebidas no filme e menos pelas premiações e reconhecimento internacional que porventura pudessem ter, como demonstra o caso de $O$ pagador de promessas e Vidas secas. 
Isso só aparece em melhor tom nas críticas com o surgimento dos primeiros filmes de Glauber Rocha, em especial com o impacto causado pelo lançamento de Deus e o Diabo na terra do sol. A inquietude cultural e politizada, a veia artística aflorada e sua visão particular do fazer cinematográfico num país considerado subdesenvolvido, tornam Glauber Rocha uma figura ímpar no contexto de produção, primeiramente baiano, para que depois ganhe o Brasil. Sobre o cineasta, Silveira escreve na crítica do filme:

Aos 25 anos, num país subdesenvolvido cinematograficamente, já é um autor internacional. Um autor brasileiro, antes. O primeiro autor cinematográfico da nacionalidade. Todo o esforço de Deus e o Diabo na Terra do Sol, esforço temático e estilístico, visa a construir um filme nacional (SILVEIRA, 1965: 356).

${ }^{6}$ Depois de ter recebido o Opera Prima, prêmio do XIII Festival Internacional de Cinema de Karlovy Vary, na Tchecoslováquia, em 1962, por Barravento, Deus e o Diabo na Terra do Sol coletou os seguintes prêmios internacionais: Prêmio da Crítica Mexicana - Festival Internacional de Acapulco, México, 1964; Grande Prêmio Festival de Cinema Livre, Itália, 1964; Náiade de Ouro - Festival Internacional de Porreta Terme, Itália, 1964; Grande Prêmio Latino Americano - I Festival Internacional de Mar del Plata, Argentina, 1966. Fonte: http://www.tempoglauber.com.br/ glauber/Filmografia/diabo.htm
A "euforia" sobre o cinema nacional surge em Silveira a partir do momento em que ele percebe em Glauber Rocha um cineasta com pretensões artísticas mais elevadas, com posições próprias sobre a sociedade brasileira e também um pensamento conceitual sobre o cinema que queria realizar, estando essas inquietações e ideias perceptivelmente presentes no filme. $O$ texto, publicado um ano depois do lançamento do filme, se apega às marcas imanentes da obra, sem que Silveira precise se basear nas premiações e na então consagração do cineasta num âmbito internacional ${ }^{6}$. E também reconhece a dimensão autoral do trabalho desenvolvido pelo cineasta no sentido de dotar seus filmes de certa personalidade que refletia seu pensamento, além de manter nas obras a temática do nacional que o crítico tanto prezava. É preciso levar em consideração também a proximidade que ambos mantinham no cenário cultural baiano, sendo Glauber tido como um discípulo do renomado crítico (CARVALHO, 1999), apesar de certas distinções na forma como enxergavam o cinema.

\section{Considerações finais}

A crítica que Walter da Silveira exercia não era engajada e nem atrelada a um projeto modificador da sociedade e do cinema enquanto atividade de mobilização, mesmo que ele pudesse defender quem assim se colocasse. De forma mais combativa, o pensamento de Glauber Rocha está mais atrelado a toda uma inquietação de insurgência desses novos cineastas que queriam modificar a face do cinema brasileiro.

O engajamento de Silveira, por outro lado, era de outra natureza, estava na própria consolidação do cinema como arte que precisava ser vista com propriedade e um mínimo de conhecimento e visão crítica, algo que ele tentava dispor ao público através de seus textos e de todo o trabalho desenvolvido em torno do cinema. Um projeto de caráter pedagógico, portanto, que visava à formatação de um olhar aguçado para a apreciação do bom cinema.

Certamente que o filme nacional passava por esse crivo, num equilíbrio muito interessante entre consideração e olhar crítico, entre a torcida para que desse certo e as cutucadas críticas que não deixava de proferir quando se sentia incomodado. Apesar de conhecer as dificuldades de produção do cinema nacional, da sua vocação pouco comercial, dos problemas de financiamento, da precariedade dos estúdios e dos meios de produção de cinema, Silveira, como observador exigente, refletia sobre esse cinema num misto de distanciamento e torcida. As configurações contextuais que cercavam as críticas de Walter da Silveura foram, portanto, fundamentais para se compreender a recepção do crítico a esse cinema brasileiro e baiano.

Uma das principais características da obra crítica de Silveira, e que se percebe nesse pequeno percurso de análise que apresentamos aqui, é a ponderação e reflexão que ele faz do lugar do cinema brasileiro em relação à capacidade estilística e temática de se estabelecer como produção consistente, importante, promissora. 


\section{Referências Bibliográficas}

BORDWELL, David. Making meaning: inference and rhetoric in the interpretation of cinema. USA: Harvard University Press, 1991.

CARVALHO, Maria do Socorro. Imagens de um tempo em movimento: cinema e cultura na Bahia nos anos JK (1956-1961). Salvador: EDUFBA, 1999.

CUNHA, Tito Cardoso e. Argumentação e crítica. Coimbra: MinervaCoimbra, 2004.

PEREIRA, Antonio Marcos. Eu era um crítico juvenil. In: QUEIROZ, Milena Brito de (Org). Leituras possíveis nas frestas do cotidiano. Salvador: FUNCEB, 2012.

ROCHA, Glauber. Revolução do Cinema Novo. Rio de janeiro: Alhambra/Embrafilme, 1981.

SETARO, André. Escritos sobre cinema: trilogia de um tempo crítico. (Org: Carlos Ribeiro). Salvador: Udufba: 2010. 3 v.

SILVEIRA, Walter da. (1943). Esta é a hora do Cinema Nacional. In:

Walter da Silveira. O eterno e o efêmero. (Org: José Umberto Dias). Salvador: Oiti Editora e Produções Culturais LTDA, 2006. V. 1, p. 92-4.

- (1969). Por uma crítica responsável. In:

Walter da Silveira. O eterno e o efêmero. (Org: José Umberto Dias). Salvador: Oiti Editora e Produções Culturais LTDA, 2006. V. 3, p. 37-8.

STAIGER, Janet. Perverse spectators: the practices of film reception. New York: New York University Press, 2000.

Interpreting films: studies in the historical reception. Princeton, New Jersey: Princeton University Press, 1992.

\section{Críticas analisadas}

SILVEIRA, Walter da. (1953a). O Cangaceiro. In: Walter da Silveira. O eterno e o efêmero. (Org: José Umberto Dias). Salvador: Oiti Editora e Produções Culturais LTDA, 2006. V. 1, p. 289.

. (1953b) Sinhá Moça. In: Walter da

Silveira. O eterno e o efêmero. (Org: José Umberto Dias). Salvador: Oiti Editora e Produções Culturais LTDA, 2006. v. 1, p. 301.

. (1954). Floradas na Serra. In: . Walter da Silveira. O eterno e o efêmero. (Org: José Umberto Dias). Salvador: Oiti Editora e Produções Culturais LTDA, 2006. V. 1, p. 396.

In:

(1959a). Estranho Encontro: pequena obra de um aprendiz. . Walter da Silveira. O eterno e o efêmero. (Org: José Umberto Dias). Salvador: Oiti Editora e Produções Culturais LTDA, 2006. V. 2, p. 70.

(1959b). Redenção: passado e futuro do cinema na Bahia. In: Walter da Silveira. O eterno e o efêmero. (Org: José Umberto

Dias). Salvador: Oiti Editora e Produções Culturais LTDA, 2006. V. 2, p. 73.

(1965). Deus e o Diabo na Terra do Sol. In:

Walter da Silveira. O eterno e o efêmero. (Org: José Umberto Dias). Salvador: Oiti Editora e Produções Culturais LTDA, 2006. V. 2, p. 353. 